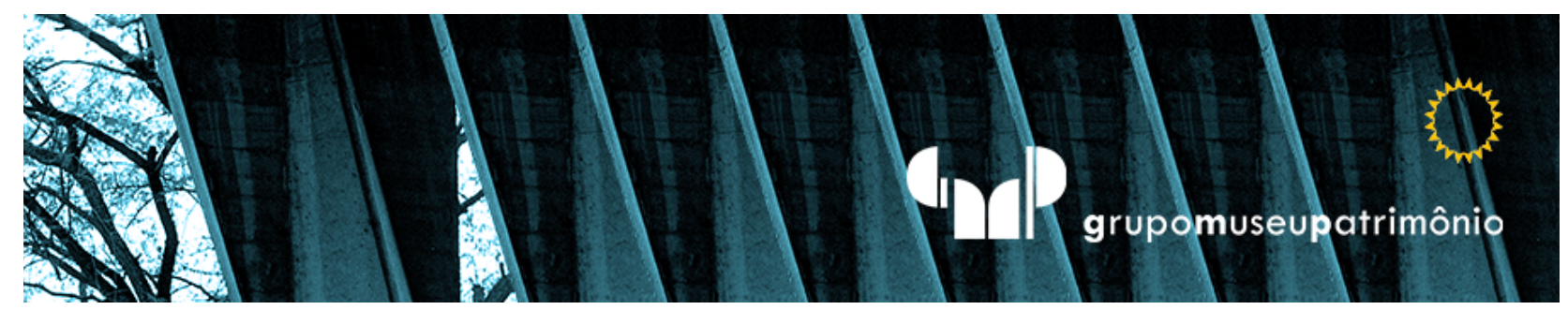

\title{
Dispor para funcionar
}

\author{
Dispor para funcionar
}

\section{Assembling in order to work}

Amanda Areias

Fotógrafa, Mestranda pela Universidade Presbiteriana Mackenzie.

São Paulo, Brasil. amandaareiasphoto@gmail.com 


\title{
Resumo
}

A série "Dispor para Funcionar" aplica-se a fugir do lugar comum ao investigar as feiras livres da cidade de São Paulo, Brasil. Comumente vistas como um território ideal e vívido, como lugar de intercâmbio e convivência pacífica em meio a uma selva de pedra, estes mercados de rua são, antes de tudo, lugar de contradição e conflito com o seu entorno. A série investiga as regras adotadas pelos feirantes na tentativa de amenizar tais embates. O que vemos é um espaço temporário mas visualmente complexo, intenso e fantástico, um cenário estético com uma profusão de cores, formas e linhas que tentam organizar o caos.

Palavras-Chave: Feira-livre. São Paulo. Espaços Urbanos. Organização. Imaginário.

\section{Resumen}

La serie "Dispor para funcionar" pretende escapar del lugar común mientras investiga los mercados callejeros de São Paulo, Brasil. Comúnmente vistos como un territorio ideal y vivo, como un lugar de intercambio armónico y convivencia en medio de una selva de piedra, estos mercados de calle son, ante todo, un lugar de contradicción y conflicto con su entorno. La serie investiga las reglas adoptadas por los comerciantes del mercado en un intento de minimizar tales conflictos. Lo que hemos encontrado es un ambiente temporal, pero visualmente complejo, intenso y fantástico, un entorno estético con una fusión de colores, formas y líneas que intentan organizar el caos.

Palabras-Clave: Feria Libre. São Paulo. Espacios Urbanos. Organización. Imaginario.

\begin{abstract}
The series "Assembling in order to work" intends to escape from the common place while investigating the street markets of São Paulo, Brazil. Commonly seen as an ideal and vivid territory, place of harmonic exchange and coexistence in the middle of a concert jungle, these streets markets are, first and foremost, a place of contradiction and conflict with its surroundings. The series investigates the rules adopted by market traders in an attempt to minimize such conflicts. What we have found is a temporary but visually complex, intense and fantastic environment, an aesthetic setting with a fusion of colors, shapes and lines that attempt to organize the chaos.
\end{abstract}

Keywords: Street Market. São Paulo. Urban Spaces. Organization. Imaginary. 


\section{INTRODUÇÃO}

Listras são ritmo, como música, que pode além de harmonia e prazer, desembocar no ruído, deflagração e loucura

Michel Pastoureau

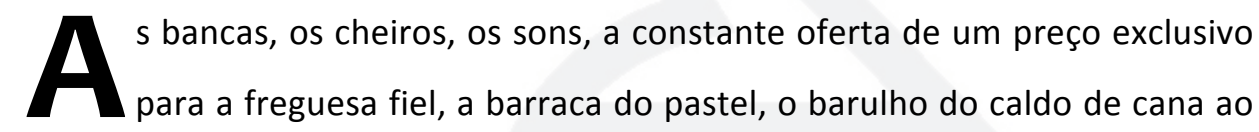
fundo, todos esses elementos fazem parte do imaginário do paulistano quando o assunto é a feira livre. Mercado informal originalmente movimentado pelos portugueses por meio do escambo de mercadorias, as feiras livres da cidade de São Paulo passaram por inúmeras transformações, mas continuam a funcionar desde sua origem como nódulos vitais de mediação entre a produção agrícola de alimentos e o consumidor. Em 2014, as feiras paulistanas completaram cem anos de organização oficial. De acordo com o engenheiro agrônomo Hélio Junqueira e a economista Marcia Peetz, autores do livro 100 
Anos de feiras livres na cidade de São Paulo (2015), a construção mal planejada de centros de distribuição na cidade, no início do século XX, gerou uma crise de abastecimento e com ela a alta dos alimentos. No ano de 1914, a reivindicação dos movimentos anarco-sindicalistas por melhores preços levou o Prefeito Washington Luís Pereira de Souza a criar os mercados francos isentos de impostos - como forma de baratear gêneros de primeira necessidade (Junqueira \& Peetz, 2015).

A história das feiras livres na cidade segue sendo marcada ora por momentos de ascensão, ora por momentos de conflito. Ainda segundo Junqueira e Peetz (2015), em 1948 o Prefeito Paulo Lauro decretou a instalação de no mínimo uma feira semanal em cada bairro ou subdistrito da cidade. $\mathrm{Na}$ década de 1960, contudo, inicia-se um período conturbado para os mercados ao ar livre que passam a enfrentar a tecnoburocracia, a industrialização e o planejamento rigoroso do desenvolvimento de São Paulo. Nas décadas seguintes os obstáculos são os supermercados e a proliferação na cidade dos chamados sacolões (2015).

Apesar das dificuldades, as feiras resistem totalizando mais de 850 mercados itinerantes espalhados em locais diversos, funcionando de terça a domingo e empregando um quadro de aproximadamente quarenta mil pessoas (Sato, $2007,95)$. Assume-se que este é um ambiente plural, aberto, em que pessoas de diversos contextos se encontram num intercâmbio tradicional e vívido. A Secretaria do Desenvolvimento, Trabalho e Empreendedorismo (2014) afirma, por exemplo, em tom otimista, que as feiras livres paulistanas são ${ }^{1}$ "permeadas pela interação social, pela convivência harmônica entre as diferentes etnias e classes sociais e pelo mais autêntico polo de convivência intergeracional”. Para as gestões municipais, o desafio que se impõe, contudo,

\footnotetext{
${ }^{1}$ Editorial publicado no site da Prefeitura Municipal de São Paulo em ocasião do centenário da existência formal das feiras livres, em 2014. Disponível em <http://www.prefeitura.sp.gov.br/cidade/secretarias/upload/trabalho/2014\%20100\%20ANOS\% 20FEIRAS.pdf> Acesso em 29 Jan 2018.
} 
é o de se empreender esforços e medidas para essa coexistência harmônica das feiras com a estrutura urbana da metrópole em meio a um crescimento constante e desenfreado. As feiras livres enquanto espaço/rua ocupada são, antes de mais nada, lugar temporário de contradição e conflito com o seu entorno. Higiene, condições insalubres de trabalho, lixo nos entornos, obstrução de vias de trânsito e ruídos são alguns dos desafios impostos à administração pública.

Na tentativa de minimizar tais conflitos, os feirantes vêm adotando, desde 2007 , normas que regularizam a montagem das feiras, a ocupação dos espaços e sua estrutura. Algumas diretrizes incluem a localização das feiras em áreas que não apresentem grande número de postes e edifícios e que permitam o estacionamento dos veículos dos usuários e feirantes. Sobre os produtos, todos os alimentos comercializados nas feiras livres devem estar protegidos da contaminação por meio da utilização de dispositivos apropriados.

Nessa contínua organização, destacam-se as regras que determinam o tamanho e a cor das barracas para os 21 diferentes grupos de produtos comercializados nas feiras. Para o grupo 1 constituído de verduras, legumes, raízes, tubérculos e tomate, as cores estabelecidas são verde e branco. A mesma cor deve ser observada pelo grupo 14 de água de coco e bebidas em geral, e pelo grupo 20 de flores naturais e artigos correlatos.

Os grupos 3, 5, 6, 7 e 15 devem adotar toldo e anteparos listrados nas cores amarela e branca. Tais grupos correspondem respectivamente à barraca de batata, cereais, mel, enlatados, farinhas e temperos em geral; barraca de banana; barraca de ovos; barraca de macarrão, queijo ralado, e outros alimentos industrializados; e à barraca de comidas típicas em geral, doces caseiros e lanches rápidos.

Toldo e anteparos listrados nas cores azul e branca são designados, por sua vez, aos grupos $4,16,17,18,19$ e 21 . Tais grupos correspondem às frutas frescas em geral, (exceto banana que possui barraca exclusiva); utensílios domésticos em geral; armarinhos, bijuterias, brinquedos, produtos para 
limpeza e higiene pessoal; roupas em geral, roupas de cama, toalhas de mesa e banho; calçados em geral, cintos e bolsas; produtos diversos e serviços de reparo de equipamentos e utilidades domésticas em geral.

Finalmente, grupos $2,8,9,10,11,12$ e 13 são orientados a adotar toldo na cor vermelha e anteparos listrados nas cores vermelha e branca. Seus produtos incluem cebola, alho, cereais em grãos, café, mel, coco ralado, enlatados, farinhas em geral, temperos para alimentos em geral, todos industrializados; laticínios (produtos derivados do leite) industrializados, margarinas, conservas em geral, frutas secas e cristalizadas, azeitonas e picles, bacalhau e outros peixes secos ou salgados; embutidos industrializados em geral (salsichas, linguiças, paios, salames e outros tipos de frios), bacalhau e outros peixes secos ou salgados, carnes-secas, salgadas ou defumadas, banhas e gorduras comestíveis, pertences para feijoada; produtos alimentícios regionais industrializados; pescados de toda espécie resfriados; aves, vísceras e miúdos de animais de corte e cortes de carne suína; pastel e salgados diversos fritos na hora.

Listras se misturam ao colorido dos alimentos e fazem jus à fala de Michel Pastoureau sobre elas: "[Listras] são ritmo, como música, que podem, além de trazer harmonia e prazer, desembocar no ruído, deflagração e loucura" (Pastoureau, 1991, 114). Uma profusão de cores, formas e linhas constantemente se harmonizam e se encontram, para logo depois se desfazerem. Dispor Para Funcionar volta-se então para essas novas configurações estéticas e em meio ao caos, retrata a tentativa de se organizar o quase inorganizável. 


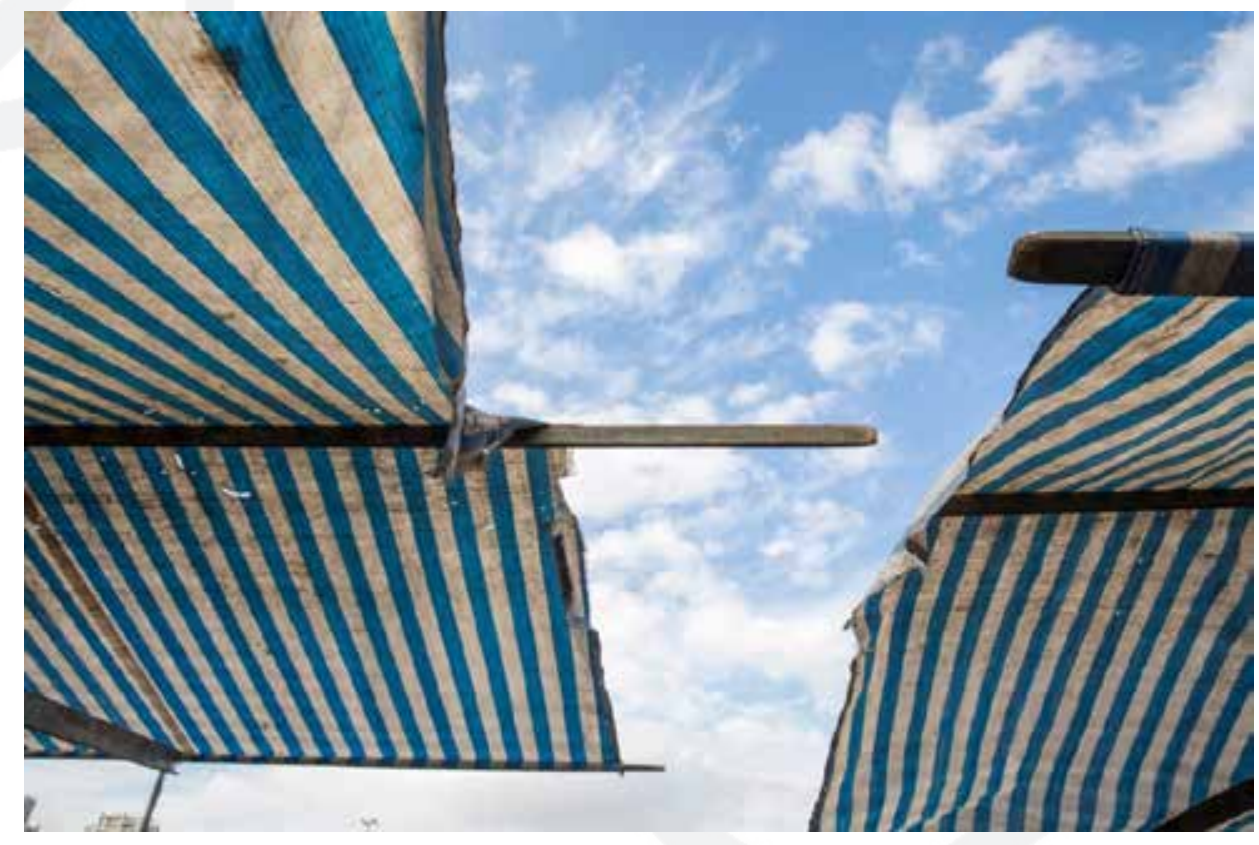

Figura 1

Fonte: Amanda Areias.

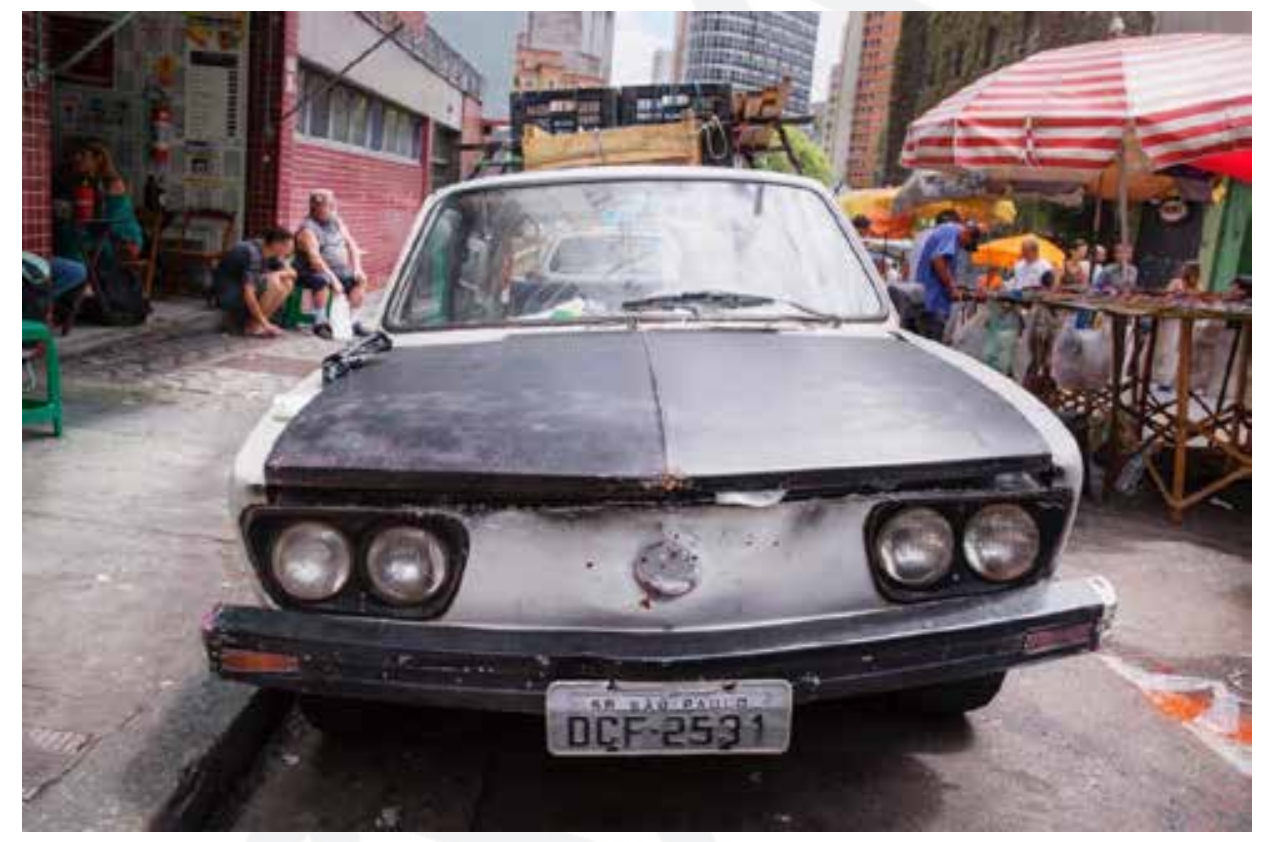

Figura 2

Fonte: Amanda Areias. 


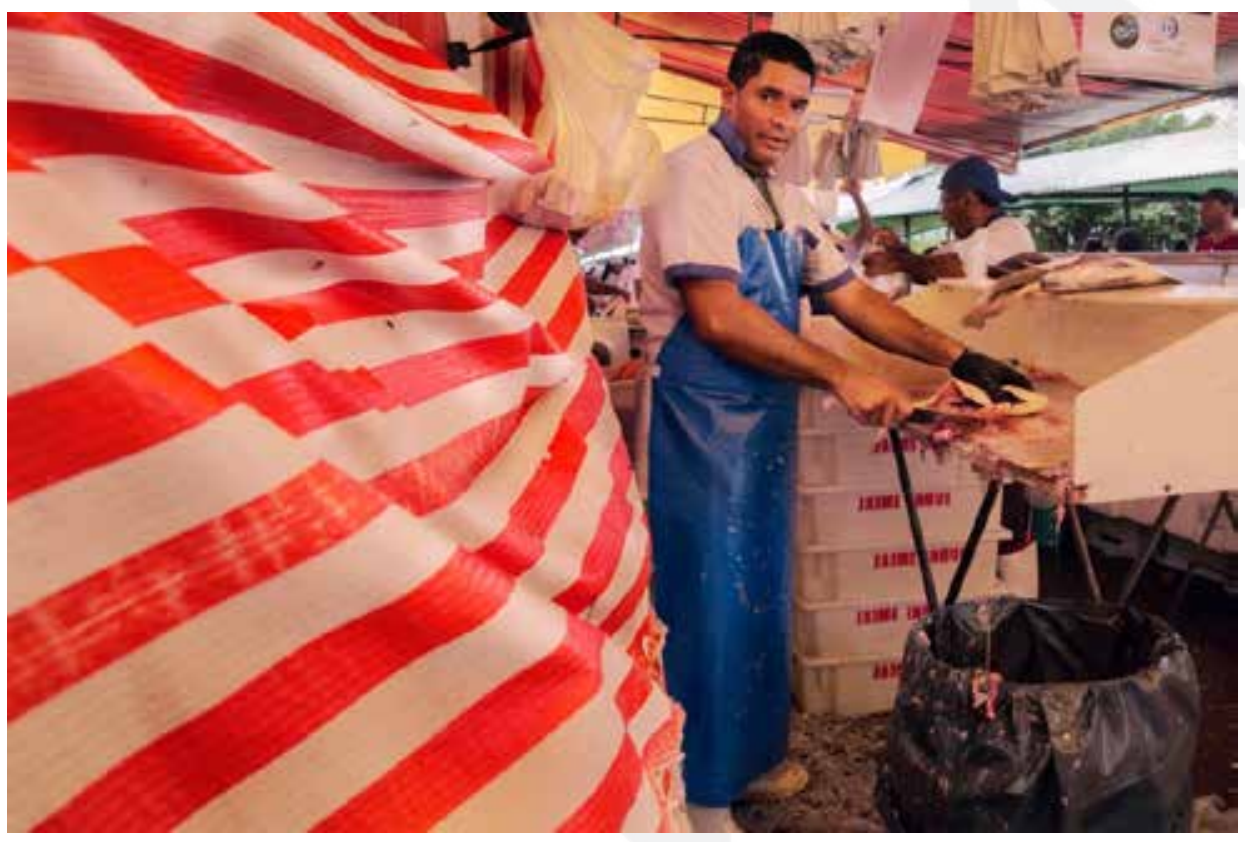

Figura 3

Fonte: Amanda Areias.

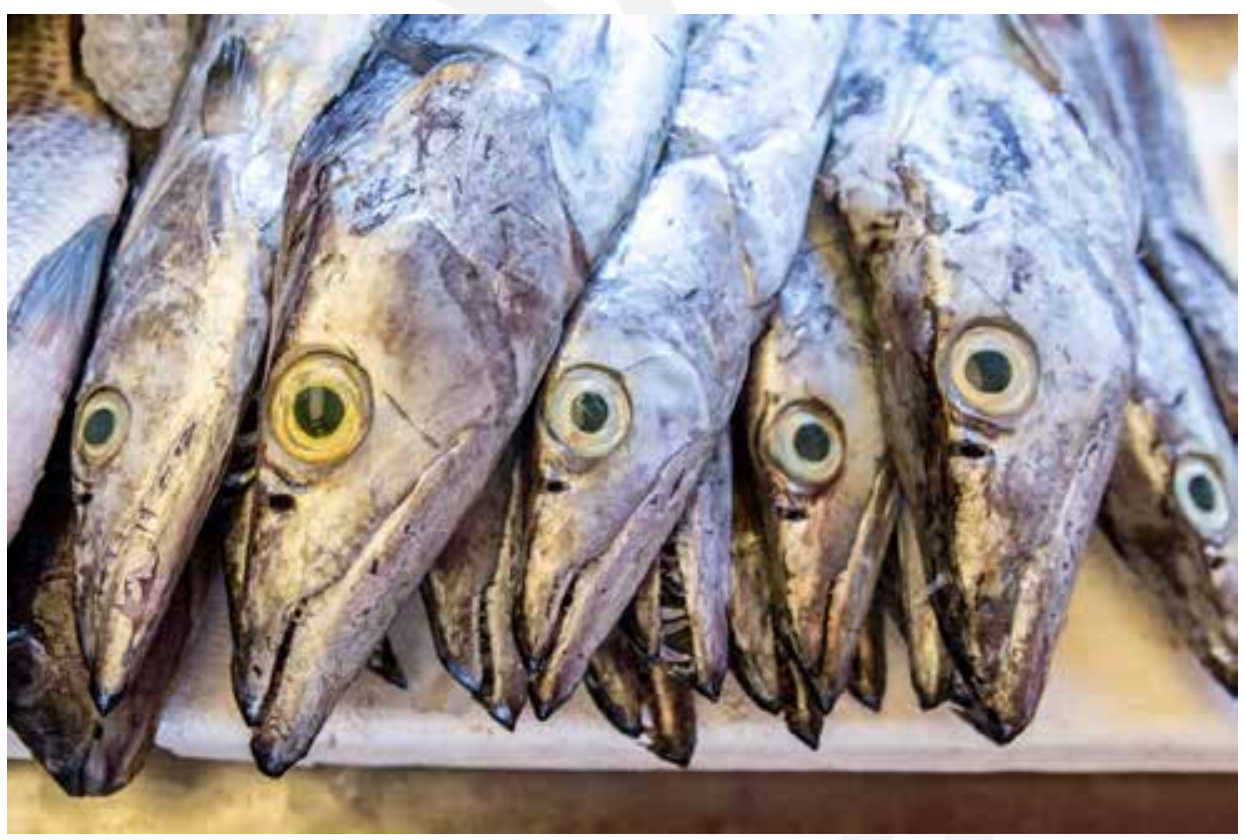

Figura 4

Fonte: Amanda Areias. 


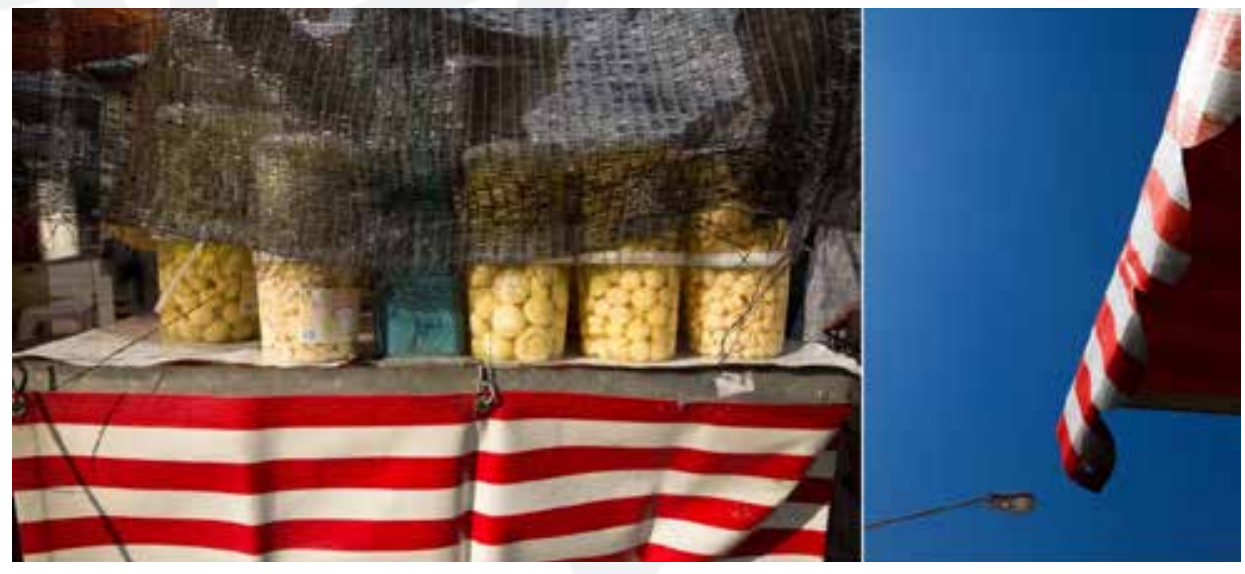

Figuras 5 e 6

Fonte: Amanda Areias.

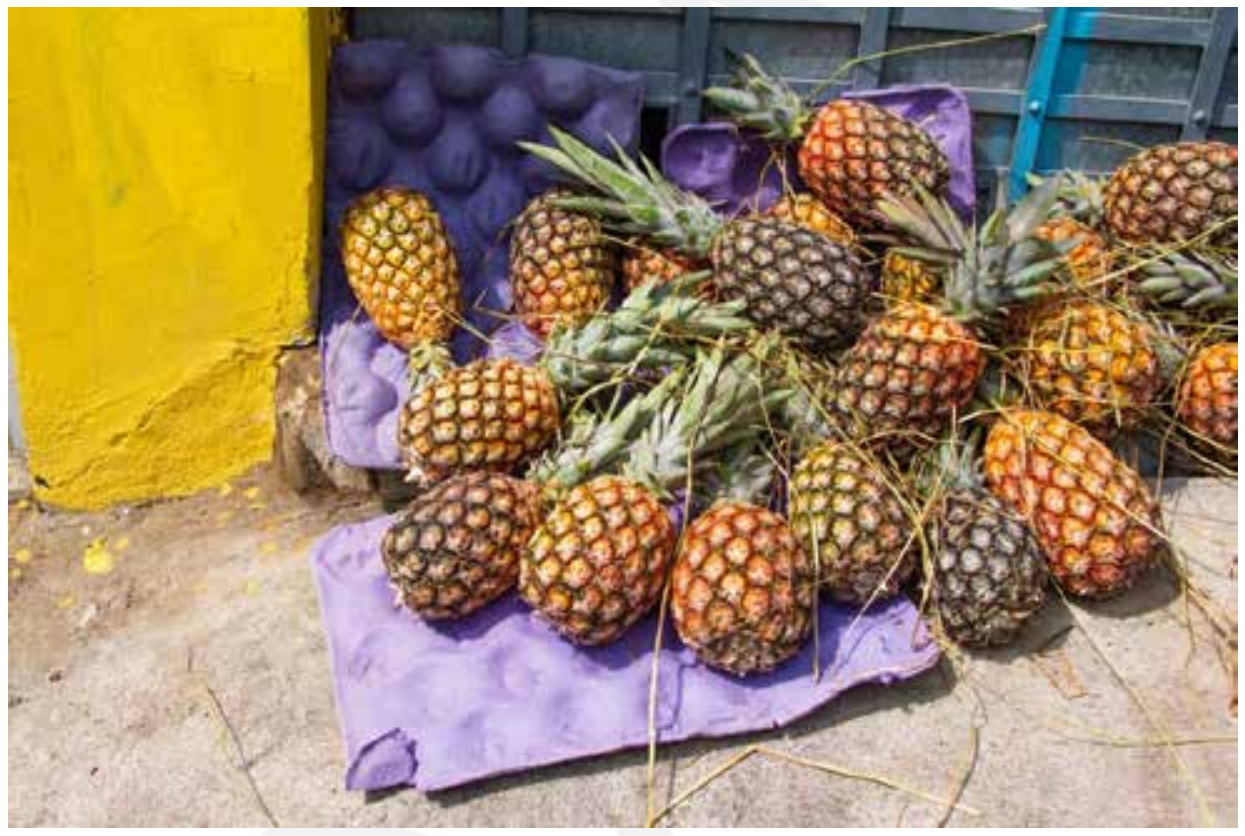

Figura 7

Fonte: Amanda Areias. 


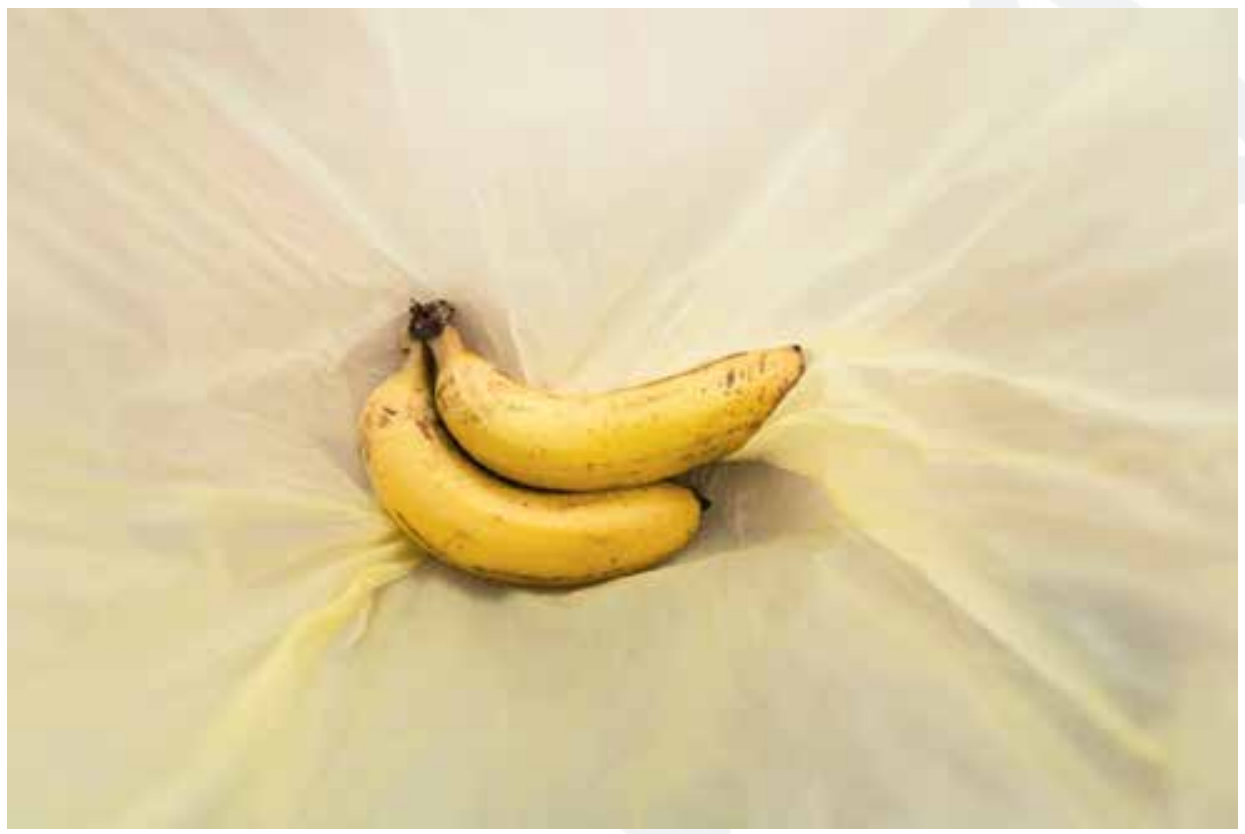

Figura 8

Fonte: Amanda Areias.

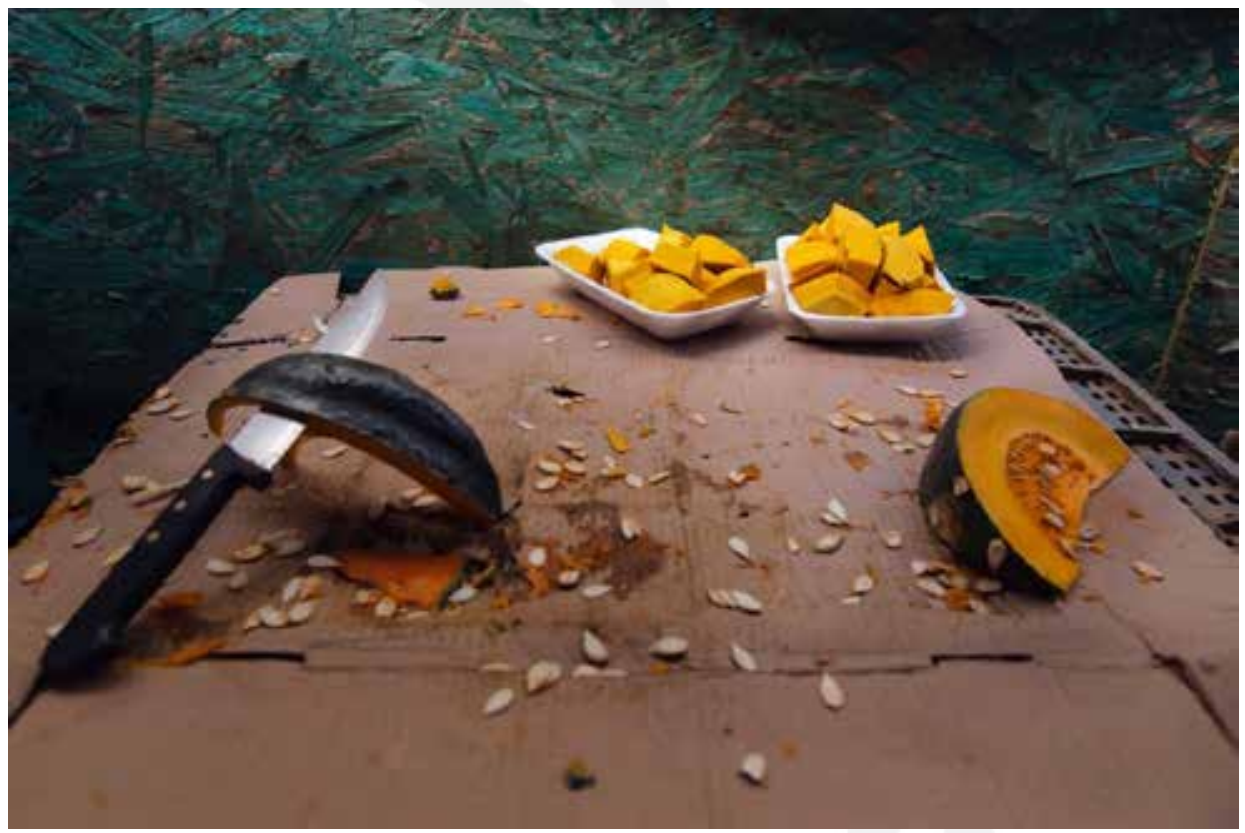

Figura 9

Fonte: Amanda Areias. 


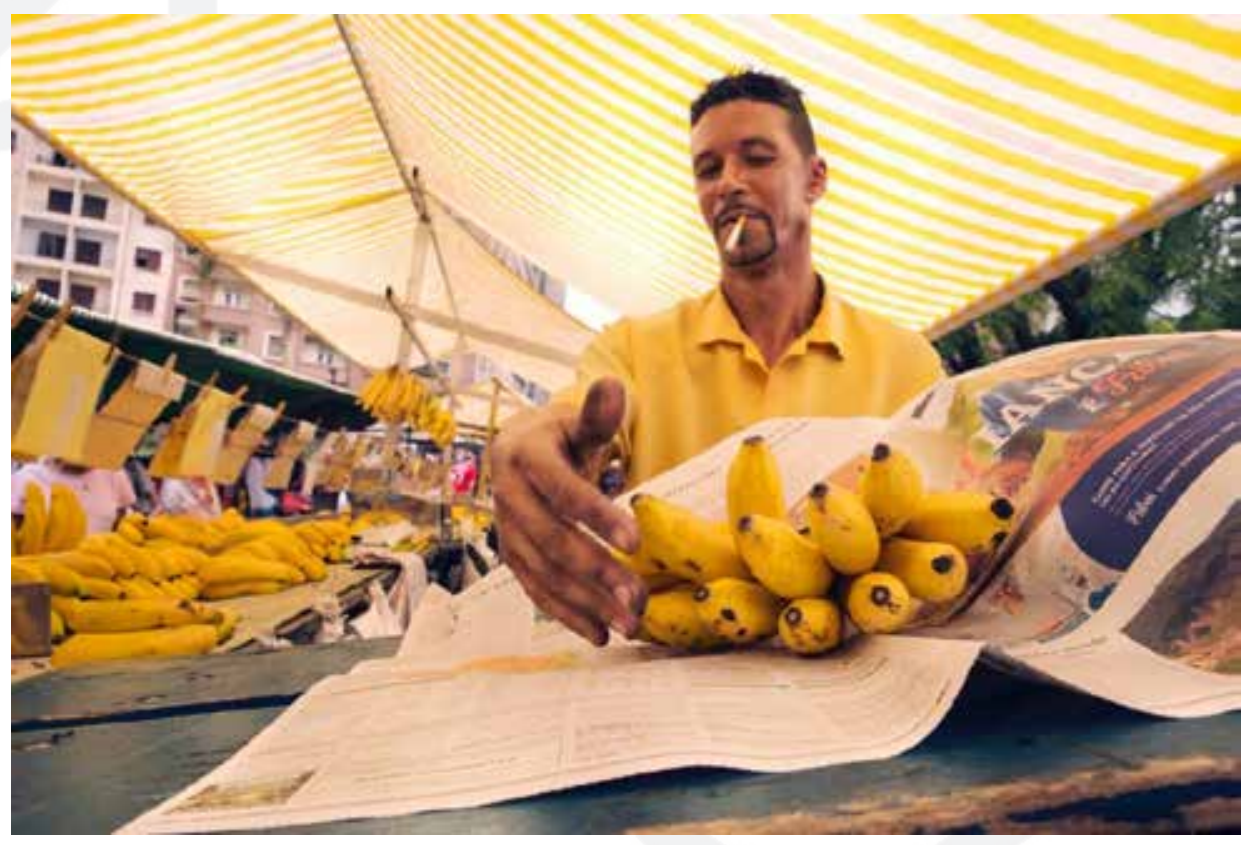

Figura 10

Fonte: Amanda Areias
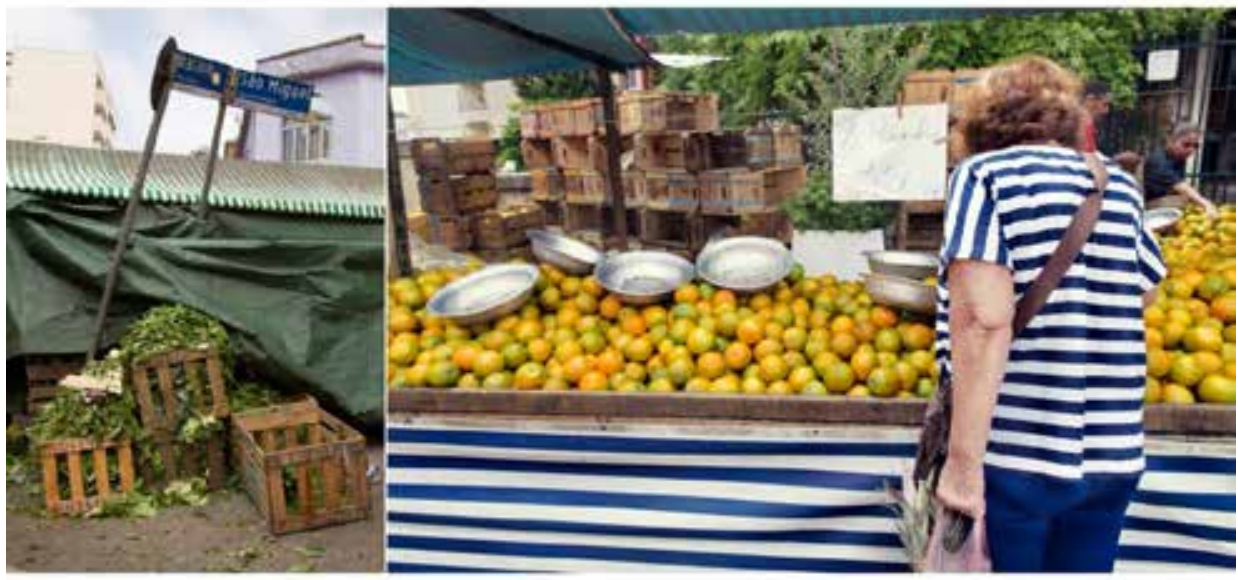

Figuras 11 e 12

Fonte: Amanda Areias. 


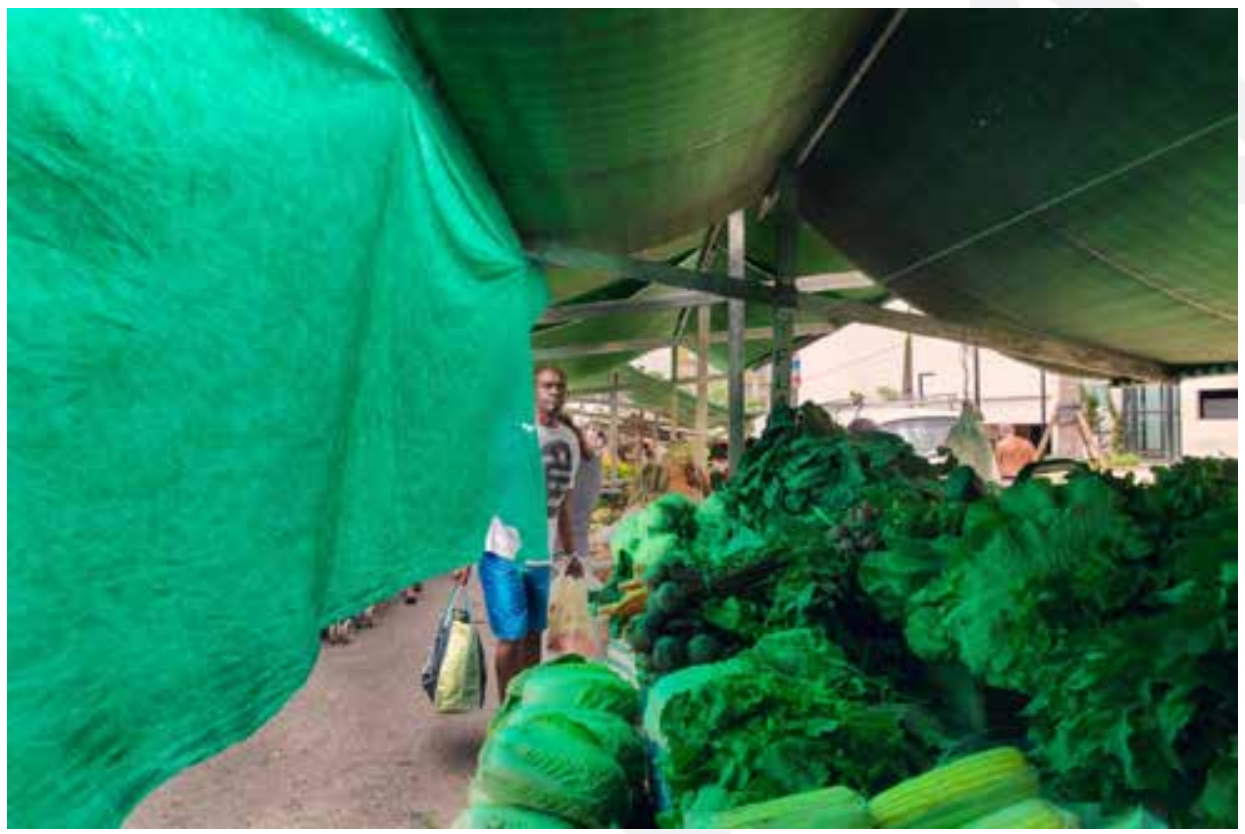

Figura 13

Fonte: Amanda Areias.

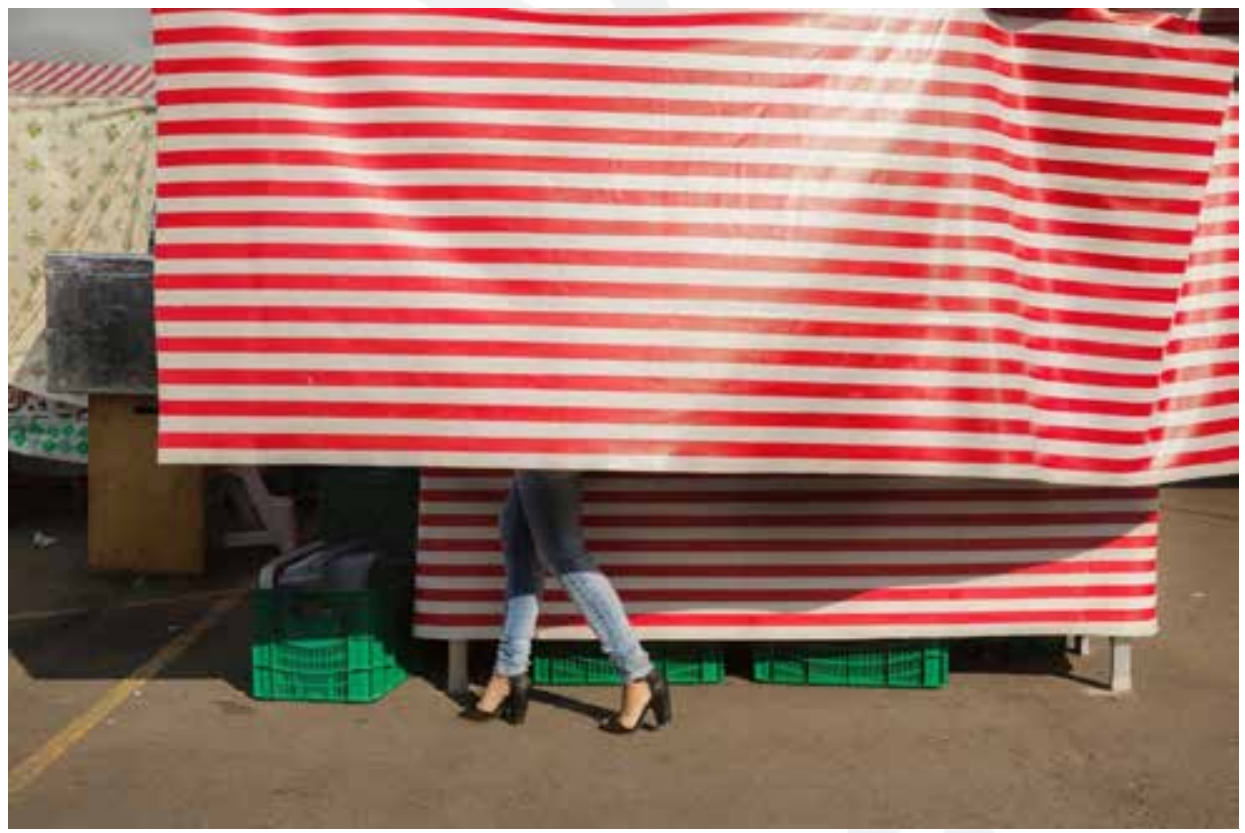

Figura 14

Fonte: Amanda Areias. 


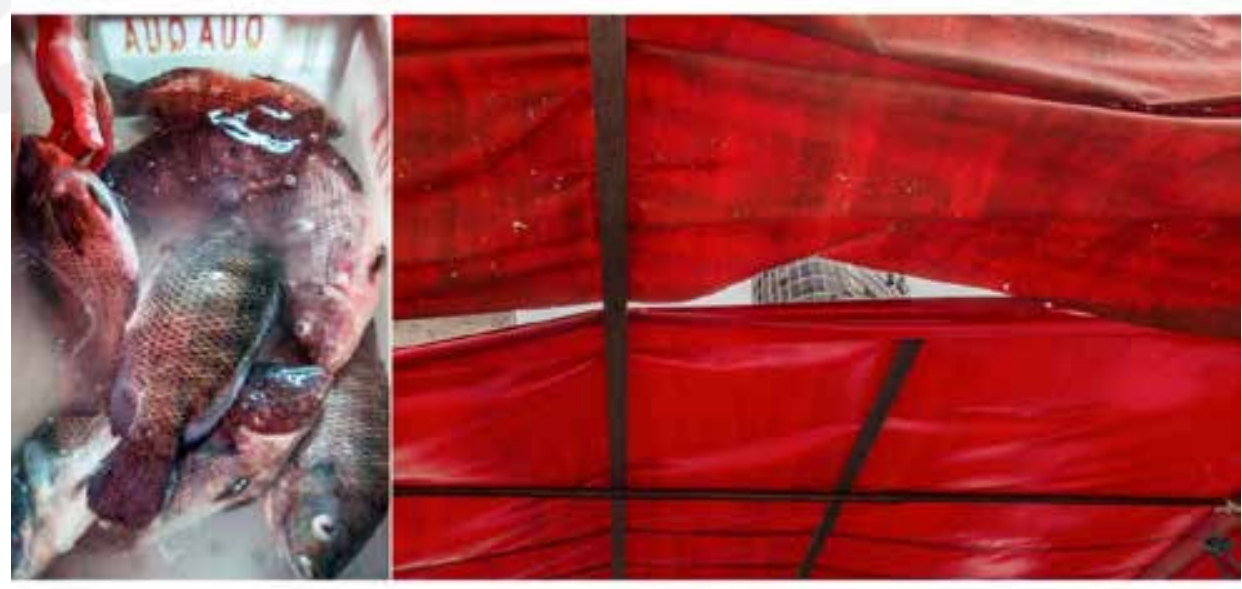

Figuras 15 e 16

Fonte: Amanda Areias. 


\section{BIBLIOGRAFIA CITADA}

JUNQUEIRA, A. H.\& PEETZ, M. da Silva. 100 anos feiras livres na cidade de São

Paulo. São Paulo: Via Impress Edições de Arte, 2015.

PASTOUREAU, Michel. The Devil's Cloth: a history of strips. New York:

Washington Square Press, 1991.

SATO, Leny. Processos cotidianos de organização do trabalho na feira livre. Psicologia \& Sociedade; 19, Edição Especial 1: 95-102, 2007. Disponível em<http://www.scielo.br/pdf/psoc/v19nspe/v19nspea13.pdf>. Acesso em 17 de outubro 2017.

SECRETARIA DO DESENVOLVIMENTO, TRABALHO E EMPREENDEDORISMO. 100 Anos de Feira livre em São Paulo. São Paulo: Prefeitura do Município de São Paulo, 2015. Disponível em <http://www.prefeitura.sp.gov.br/cidade/secretarias/upload/trabalho/2 014\%20100\%20ANOS\%20FEIRAS.pdf> Acesso em 29 de janeiro 2018.

\section{Fontes eletrônicas e sites}

Decreto № 48.172, de 6 de Março de 2007. São Paulo: Prefeitura do Município de São Paulo, 2007. Disponível em <http://www3.prefeitura.sp.gov.br/cadlem/secretarias/negocios_juridic os/cadlem/integra.asp?alt=07032007D\%20481720000> Acesso em 29 de janeiro 2018.

FEIRA MAPS. Disponível em <http://www9.prefeitura.sp.gov.br/secretarias/sdte/pesquisa/feiras/list a_completa.html> Acesso em 17 de outubro 2017. 